\title{
Medievalista
}

Online

$24 \mid 2018$

Número 24

\section{La cruzada en las fuentes cronísticas castellanas de la Guerra de Granada}

Tese de Doutoramento em História apresentada à Universidade de Extremadura (Espanha), Julho de 2017. Orientação do Professor Doutor Manuel Rojas Gabriel

José Fernando Tinoco Díaz

\section{(2) OpenEdition}

1 Journals

Edición electrónica

URL: http://journals.openedition.org/medievalista/1710

DOI: 10.4000/medievalista. 1710

ISSN: 1646-740X

Editor

Instituto de Estudos Medievais - FCSH-UNL

Referencia electrónica

José Fernando Tinoco Díaz, « La cruzada en las fuentes cronísticas castellanas de la Guerra de Granada », Medievalista [En línea], 24 | 2018, Publicado el 16 marzo 2019, consultado el 23 septiembre 2020. URL : http://journals.openedition.org/medievalista/1710; DOI : https://doi.org/10.4000/ medievalista. 1710

Este documento fue generado automáticamente el 23 septiembre 2020.

Mediavalista está licenciado com uma Licença Creative Commons - Atribuição-NãoComercial 4.0 Internacional. 


\title{
La cruzada en las fuentes cronísticas castellanas de la Guerra de Granada
}

Tese de Doutoramento em História apresentada à Universidade de Extremadura (Espanha), Julho de 2017. Orientação do Professor Doutor Manuel Rojas Gabriel

\author{
José Fernando Tinoco Díaz
}

\section{NOTA DEL EDITOR}

Data recepção do artigo / Received for publication: 24-01-2018

Dentro de la historiografía medieval europea actual, se puede afirmar que la preminencia de las corrientes de carácter "pluralistas" de definición del concepto de cruzada ha originado un marco de estudio demasiado amplio, donde cualquier intervención militar con rasgos de exaltación religiosa puede definirse prácticamente en estos términos. Esta situación ha dificultado la correcta comprensión de una realidad tan compleja como lo fue este fenómeno, que tuvo evidentes implicaciones ideológicas, tanto doctrinales, como espirituales. En el caso de la Península Ibérica, muchos han sido los historiadores actuales que han defendido el carácter cruzado de la llamada Reconquista hispana. Al no estar frente a un concepto absoluto, sino ante un convenio historiográfico, durante las últimas décadas se han generado múltiples interpretaciones de la realidad a la que hace referencia este término. Algunas de ellas han incidido en su identificación como una muestra de la expresión más amplia del movimiento cruzadista, dejando al margen de esta identificación los rasgos más singulares de la Historia medieval peninsular. Aunque el tratamiento de ambas nociones fue semejante en determinados momento, e incluso ambas pudieran aparecer unidas en torno al desarrollo de una construcción doctrinal homogénea de manera puntual, nunca fueron realidades equitativas en realidad. Parece hacerse necesario, por tanto, una acotación y redefinición de los conceptos de cruzada y Reconquista que 
tenga en cuenta realmente la expresión ideológica concreta a la que hacen referencia ambos términos.

Partiendo de estas premisas, la meta principal de este trabajo de Tesis Doctoral ha sido la de revisitar uno de los problemas historiográficos de más importancia en la actual Historia Medieval peninsular. La óptica que lo ha regido no ha buscado determinar una respuesta firme a la definición de la cruzada y la Reconquista, sino abrir una nueva vía de reflexión sobre la amplia realidad histórica a la que hacen referencia ambos conceptos. Para lograr tal menester, se ha optado por ahondar en el tratamiento del trasfondo doctrinal de uno de los acontecimientos más importantes de la historia medieval hispana: la Guerra de Granada (1482-1492). Este conflicto, acaecido entre el reino de Castilla y el emirato nazarí de Granada, ha sido tradicionalmente considerado como la última gran contienda de la Edad Media hispana y el capítulo final de la Reconquista. Con la victoria cristiana sobre el bando nazarí concluyó con la integración del último reino musulmán de la Península Ibérica en el conjunto de territorios gobernados por los Reyes Católicos (1474-1504).

Tradicionalmente, el tratamiento de la Guerra de Granada estuvo marcado por el desarrollo de estudios históricos de una gran carga nacionalista que consideraban el reinado de los Reyes Católicos como el germen de la grandeza del estado español. A partir del último cuarto del siglo XX comenzaron a multiplicarse los trabajos de análisis y síntesis centrados de forma singular en la contienda castellano-nazarí. Estas investigaciones realmente incidieron en las diversas facetas de la contienda y el contexto donde se produjo, lo que puso de manifiesto esta guerra mantenía muchos de los rasgos propios del periodo medieval pero también evidenciaba rasgos novedosos, como bien la definió M.A. Ladero Quesada. Tanto la conducción de un ejército que estaba en camino de convertirse en casi permanente y semiprofesional, como por las maniobras políticas y diplomáticas que atrajeron la atención de pensadores como el italiano Nicolás Maquiavelo (1469-1527), han sido rasgos lo suficientemente novedosos para defender tal afirmación. A finales de esta década, el carácter de la Guerra de Granada parecía estar ya completamente establecido como se determina en trabajos recientes como los del hispanista J. O'Callaghan. Sin embargo, el componente ideológico y doctrinal de la contienda parece un tema especialmente atractivo que aún se presta a estudio desde una perspectiva actual. Trabajos como los realizados por J. E. López de Coca, o más recientemente R. Peinado Santaella, ponen de manifiesto la necesidad de volver a reflexionar sobre este conflicto a través del análisis de las diversas fuentes cronísticas que se hicieron eco de aquel decisivo enfrentamiento para la suerte del último estado andalusí de la Península Ibérica.

Siguiendo esta línea de trabajo, se ha optado por plantear el estudio de elementos potencialmente cruzados en las crónicas referentes a la Guerra de Granada para después comparar las referencias de los distintos autores del periodo y realizar un examen de las representaciones y el tratamiento que se le concede a la cruzada en el conflicto. Las fuentes analizadas en el presente trabajo han sido consideradas como un producto ideológico en sí mismo, un hecho retórico, social y político coherente, reflejo del sistema social al que pertenecían los autores que las compusieron. Se ha realizado una selección muy amplia, que incluye las principales crónicas castellanas de todo el siglo $\mathrm{XV}$, junto a las principales fuentes historiográficas hispánicas de los siglos posteriores a esta centuria, con el objetivo de plantear antecedentes y delimitar el alcance del impacto de estas narraciones coetáneas en la posteridad. Con el examen de 
todas estas diversas expresiones narrativas referentes a la Guerra de Granada, donde ha interesado tanto lo real como lo ficticio, lo expresado y lo silenciado, se ha pretendido abordar la dimensión comunicativa de la cronística castellana y su manifestación como ejemplo de justificación dinástica, actividad gubernativa y exaltación monárquica. Esta postura ha buscado abrir nuevos campos de análisis que amplíen el estudio de la Guerra de Granada desde una visión realmente poliédrica, procurando localizar, exponer y afrontar nuevos problemas desde una perspectiva crítica lo más amplia posible. Pero en algunos casos tal determinación también se ha traducido en el reconocimiento de la imposibilidad de dar respuesta a determinados desafíos.

De acuerdo con todo lo mencionado, esta Tesis Doctoral ha pretendido abordar las diversas facetas ideológicas expresadas por los narradores de la Guerra de Granada desde una concepción de la cruzada entendida como fenómeno poliédrico. Esto significa partir de la necesidad de establecer un marco teórico a partir del cual poder determinar las amplias bases conceptuales, historiográficas y metodologías que han guiado este análisis (Capítulos 1 a 3). La estructura de la parte analítica comienza realizando un acercamiento a la realidad social donde fue gestada la Guerra de Granada para buscar los antecedentes de dicho conflicto (Capítulo 4). Esta aproximación se inicia durante los primeros años del siglo $\mathrm{XV}$, cuando se estructuró una nueva forma de entender la relación castellana con el emirato nazarí. Tras el ascenso al trono castellano de la dinastía Trastámara (1369), la necesidad de afianzar la autoridad de esta nueva dinastía generó importantes disputas internas al respecto de la forma en la que fue concebido el gobierno en este territorio. Estas controversias concluyeron con la victoria del bando favorable a doña Isabel en la Guerra de Sucesión Castellana (1474-1479), lo que determinó el éxito de la vía más autoritaria de definición de la soberanía real. A lo largo de este enfrentamiento, el entorno cortesano fue componiendo una representación de la nueva reina de Castilla acorde a la doctrina neogoticista y la tradicional profecía isidoriana del Planto de España. Esta retórica entendía los convulsos reinados de sus antecesores en clave finalista, algo que favoreció la interpretación de su ascenso al trono como el inicio de un nuevo kairòs para los reinos peninsulares.

6 Con el matrimonio entre el príncipe don Fernando, futuro rey de Aragón y doña Isabel de Castilla en 1469, los destinos de ambas coronas parecieron fundirse por virtud de la propia divinidad. Aunque cada uno de los monarcas conservó su independencia en las decisiones que involucraban a sus reinos, ambos reyes compartieron una idea de gobierno conjunta que sobrepasaba el mero ámbito institucional. Fruto de esta nueva perspectiva conjunta surgió una idea de monarquía de carácter cristiano que exaltaba a la fe católica como la principal razón de estado. La noción de soberanía real resultante, guiada por una especie de "máximo religioso" como lo definió L. Suárez Fernández, dejaba de manifiesto la faceta moral del gobierno de estos reyes, lo que ensalzaba su compromiso con los valores ideológicos más intrínsecos de la sociedad cristiana occidental. Entonces se vio lo idóneo de retomar las campañas contra el moro en el contexto de la Península Ibérica. El objetivo de los reyes no fue sólo acabar con la existencia del emirato nazarí de Granada para fortalecer su autoridad en un contexto de unidad territorial, sino utilizar esta victoria con vistas a reforzar una nueva política exterior conjunta guiada por un claro signo mediterráneo.

7 El siguiente apartado está dedicado al estudio de las causas que dieron lugar al estallido de las hostilidades y la perspectiva con la que estos hechos fueron recogidos por las 
crónicas contemporáneas (Capítulo 5). Estas fuentes historiográficas presentan narraciones muy ricas en referencias destinadas a reforzar el inexcusable carácter histórico de la empresa castellana frente al musulmán. En ese sentido, el conflicto activo contra los nazaríes nunca fue planteado como una simple guerra de conquista en la cronística del periodo, sino que fue definida sobre todo como una verdadera acción legítima que respondía a razones de índole histórica y jurídica. La determinación de Isabel y Fernando por iniciar las hostilidades frente a los nazaríes siempre respondió a una causa tan lícita como era la restauración del señorío cristiano sobre un territorio que pertenecía a los herederos de la dinastía goda. Asimismo, el casus belli inmediato de este conflicto entre castellanos y granadinos se situó en el ataque musulmán a Zahara de la Sierra (1481), hecho que determinó la ruptura legítimas de las treguas vigentes entre ambos reinos. El triunfo del bando cristiano en este conflicto fue resultado de la dirección personal de unos reyes que mantuvieron las bases feudales del tradicional compromiso de la sociedad castellana con la corona y supieron adaptar los medios a su disposición a la coyuntura del momento. Fruto de esta perspectiva, las referencias a los valores culturales que movieron realmente al conjunto de la sociedad castellana a participar en la empresa encabezada por Isabel y Fernando determinaron el reforzamiento del compromiso feudal y la autoridad regia de estos reyes sobre la idea de la prosecución de la recuperación de una unidad territorial de significación superior. Pero en ningún momento el credo del adversario constituyó la única causa específica para su prosecución; aunque, como resulta obvio, siempre fue un motivo subyacente importante.

8 El estudio de la dimensión cristiana de las hostilidades se ha realizado en otra sección (Capítulo 6), en la que se han analizado diversas y heterogéneas facetas de la contienda que tienen que ver con la definición doctrinal del enemigo castellano, visibles en las ceremonias de victoria o el propio trato que los nazaríes recibieron en las obras narrativas del periodo. El análisis de tales manifestaciones determina que el verdadero objetivo de estos monarcas era el de incorporar de forma paulatina el territorio granadino al dominio de la corona de Castilla. Por este motivo, sus relaciones con el enemigo musulmán siempre estuvieron marcadas por un eminente realismo político que fue más allá de cualquier exaltación de la faceta cristiana del ejército cristiano a lo largo del conflicto. Verbigracia, los acuerdos logrados con distintos dirigentes musulmanes -entre los que destacan los tratados firmados con el emir Boabdil-, junto a los pactos de rendición de diversas ciudades nazaríes firmados a lo largo de la contienda, manifiestan abiertamente el carácter jurídico de la Guerra de Granada. De hecho, la pervivencia de las creencias islámicas profesadas por los granadinos tampoco demostró ser ningún problema para los Reyes Católicos, pues la idea tradicional de guerra frente al moro en la Península Ibérica no siempre se hallaba impelida de modo obligado por una necesaria perspectiva la perspectiva religiosa.

La visión doctrinal de la contienda que transmiten las fuentes nunca dio sentido, por sí misma, a la prosecución de la Guerra de Granada. Pero sí que reforzó sobremanera la faceta cristiana del gobierno de Isabel y Fernando, permitiendo a los monarcas de Castilla y Aragón exigir el apoyo de toda la cristiandad a su causa. Esto se vio correspondido por la concesión de una serie de gracias papales entre las que destacó la bula de cruzada. El siguiente punto del trabajo profundiza en las relaciones entre los Reyes Católicos y los pontífices romanos, así como el apoyo explícito del Papado a la corona castellano-aragonesa en su conflicto frente al reino nazarí (Capítulo 7). En este apartado se tratan aspectos como la importancia económica de la bula de la cruzada 
para esta empresa o la puntual incidencia de tropas europeas y colaboración de diversos príncipes cristianos en un periodo marcado por la amenaza turca en el contexto mediterráneo. Al margen de esta perspectiva institucionalista, también se pone de manifiesto el hecho de que la propaganda castellana se sirvió de las posibilidades doctrinales en torno a la exaltación de la lucha por la defensa de la fe cristiana, para otorgar a la Guerra de Granada una significación que excedió el carácter casi exclusivamente castellano de las empresas y campañas que la precedieron. En ese sentido, la equiparación de la contienda entre castellanos y granadinos con la pugna que librara la cristiandad frente a los ejércitos otomanos, tuvo una gran repercusión en la propia definición doctrinal que adquirió la empresa bélica de Isabel y Fernando. Tal discurso pretendió transmitir la idea de que el movimiento cruzadista se estaba revitalizando en la Península Ibérica y volvía a recuperar su sentido original con la exaltación la fe católica, algo que tendría consecuencias directas en la defensa inalienable de los intereses inmediatos de los Reyes Católicos en el contexto europeo.

10 La atención sobre la faceta más escatológica mostrada por los cronistas en sus obras (Capítulo 8), ha permitido determinar realmente la faceta cruzada de la Guerra de Granada desde una visión, tanto institucional, como espiritual, conjuntando las dos perspectivas más reconocidas que tradicionalmente han copado los análisis de este concepto. Tal determinación esta irremediablemente ligada al estudio del halo milenarista en torno a la prosecución de conquista de Granada como culminación de la Reconquista hispánica. Esta perspectiva conjugaba diversos conceptos tradicionalmente unidos a la doctrina neogoticista y la propia idea de cruzada, lo cual permitió reclamar la prosecución de nuevos objetivos tras la conclusión de dicha empresa. De esta manera, el espíritu que había guiado la empresa de expansión cristiana en el ámbito peninsular tuvo oportunidad de reclamar su continuación en el norte de África como camino hacia Tierra Santa. La difusión de una corriente mesiánica de clara índole política, que pretendía avalar las pretensiones de don Fernando de Aragón de encabezar una nueva ofensiva frente al avance turco en el ámbito mediterráneo y promover a la cristiandad hacia una nueva etapa de esplendor, aseguraron su representación como gran adalid de la cristiandad occidental en esta etapa. Sin embargo, los Reyes Católicos nunca sacrificaron sus verdaderas pretensiones políticas por contribuir en una cruzada real proyectada para recuperar Jerusalén de manos otomanas. Pese a todo, el éxito de esta campaña retórica absoluto, algo que permitió a estos monarcas ser reconocidos en Europa como protectores de la Santa Iglesia Romana. Este nombramiento determinó una transferencia de la titularidad de la cristiandad a los monarcas peninsulares auspiciada por el propio papado, lo que reforzó su autoridad en el contexto italiano y desbancó a los herederos de Carlomagno de esta consideración.

11 Por todo lo dicho no puede afirmarse que la Guerra de Granada fuera una cruzada sensu stricto, aunque las diversas fuentes narrativas del periodo así pudieran reclamarlo. La percepción de estas campañas expresadas por los autores castellanos coetáneos a la contienda era realmente producto de una clara voluntad de persuadir y perpetuar una determinada doctrina política de índole cristiana. Pero la conquista del emirato nazarí estuvo ajena a cualquier idea de iniciativa popular. Ésta fue siempre una empresa de marcado carácter institucional, donde los elementos que actualmente se asocian a la idea original de cruzada sobrevivían subordinados a una realidad marcada por el paulatino reforzamiento de la autoridad real y el surgimiento de una idea de ente estatal de corte autoritario. La consideración cruzada de las campañas castellanas 
frente al emirato nazarí no supuso un verdadero cambio en la forma de considerar a los musulmanes en la Península Ibérica. Las referencias a los distintos elementos que formaban parte de la doctrina original de la cruzada aparecen desvirtuadas de su función original. De hecho, algunos de estos fundamentos entraron en contradicción con el realismo político que rigió la prosecución de este enfrentamiento. La gran habilidad que demostraron tener los servidores áulicos del entorno castellano permitió establecer una adecuación de estos mecanismos doctrinales e institucionales a una determinada realidad histórica de índole nacional, de forma que la Guerra de Granada llegó a tener una trascendencia universal en consonancia con la nueva imagen imperialista de la corona castellano-aragonesa como garante de la fe cristiana.

\section{AUTOR}

\section{JOSÉ FERNANDO TINOCO DÍAZ}

Consejo Superior de Investigaciones Científicas, Institución Milà i Fontanals, 08011, Barcelona, España

ftinoco@imf.csic.es 